\title{
The Prevalence of Hydatids of Morgagni in Surgically Managed Patients with Gynecological Conditions
}

\section{Mustafa Gazi UÇAR, ${ }^{a}$ Tolgay Tuyan ILHAN, ${ }^{b}$ Ayhan GÜL, ${ }^{a}$ Tansel ÇAKIR, ${ }^{c}$ Gülşah ALKAN DEMIR, ${ }^{a}$ Çetin ÇELIK ${ }^{a}$}

aDepartment of Obstetrics and Gynecology, Selçuk University Faculty of Medicine, Konya

${ }^{b}$ Clinic of Obstetrics and Gynecology, Mersin City Hospital,

Mersin

'Clinic of Obstetrics and Gynecology

15 July Obstetrics and Children's Hospital, Konya

Received: 17.05.2017

Received in revised form: 17.08 .2017

Accepted: 21.08.2017

Available online: 10.04.2018

Correspondence:

Mustafa Gazi UÇAR

Selçuk University Faculty of Medicine, Department of Obstetrics and Gynecology, Konya, TURKEY

mustafa_gazi_ucar@hotmail.com

\begin{abstract}
Objective: To determine the prevalence of hydatid of Morgagni (HM) and describe its clinical features in patients with gynecological conditions. Material and Methods: A prospective study was designed to investigate the prevalence of HM. The patients who underwent diagnostic or surgical procedures like laparotomy and laparoscopy to visualize the fallopian tubes for malignant or benign obstetrical/gynecological conditions at a tertiary referral health care from January 2015 to October 2016 were included in the study. We defined HM based on the direct visualization of the tubes at the time of surgery. Results: A total of 1,361 patients, 1,066 (78.3\%) premenopausal and 295 (21.7\%) postmenopausal, were included in this study. The mean age was $39.3 \pm 14.7$ years (range $18-80$ years). The overall prevalence of $\mathrm{HM}$ was $17.2 \%(\mathrm{n}=235)$ and that in premenopausal and postmenopausal women was $18.9 \%$ and $11.5 \%$, respectively. HM prevalence was significantly higher among premenopausal women compared to postmenopausal women $(\mathrm{p}=0.003)$. The majority $(\sim 96 \%)$ of the HMs were $\leq 1 \mathrm{~cm}$ and in only three cases $(0.2 \%)$ the HM exceeded $2 \mathrm{~cm}$ in diameter. Conclusion: A systematic examination and appraisal of the adnexa during pelvic surgery may help in accurately identifying such common cysts. The direct evaluation of the fallopian tubes seems to be the best method to determine the prevalence of HM since most cysts are $<1 \mathrm{~cm}$ in diameter. Since the prevalence of HM decreased after menopause, their development may be stimulated by hormones.
\end{abstract}

Keywords: Fallopian tubes; fallopian tube diseases; paraovarian cyst; prevalence

$\mathrm{T}$ he hydatid of Morgagni (HM) is one of the most common non-inflammatory conditions of the fallopian tubes. ${ }^{1} \mathrm{HMs}$ are benign, usually pedunculated, serous-type, fluid-filled, cystic structures arising from vestigial remnants of the paramesonephric ducts. They tend to be solitary, measure up to several centimeters in diameter, and attached to the fimbriated end by stalks of varying lengths.

Although the clinical significance of $\mathrm{HM}$ is unclear, a higher incidence of $\mathrm{HM}$ is observed in patients with unexplained infertility and in those with adnexal torsion. ${ }^{2,3}$ Recent data suggest that HM plays a much more important role in clinical conditions than previously thought.

The majority of HMs are incidental findings due to their small size and asymptomatic nature. Therefore, the direct evaluation of the fallopian tubes 
during surgery can help determine the prevalence of HM, as in our study. The overall prevalence of $\mathrm{HM}$ remains elusive largely due to the lack of rigorous studies, although they have been reported in a limited number of patients among the infertile, pediatric and adolescent populations. . $^{2,45}$

$\mathrm{HM}$ is a common condition that attracts little attention but is potentially significant to warrant further investigations. In this study, the prevalence of HM was determined and its clinical features were described.

\section{MATERIAL AND METHODS}

A prospective study was designed to investigate the prevalence of $\mathrm{HM}$ in a tertiary referral hospital at the Selçuk University. This study included all patients who underwent diagnostic or surgical procedures like laparotomy and laparoscopy to visualize their fallopian tubes for malignant or benign gynecological conditions at the Department of Obstetrics and Gynecology of the Faculty of Medicine from January 2015 to June 2016. We defined $\mathrm{HM}$ on the basis of the direct visualization of the tubes at the time of surgery. The patients with paratubal cysts (PTCs) other than HM, those who underwent recurrent surgery in our hospital during the study period, those who underwent tubal surgery previously, and those in whom it was not possible to assess the fallopian tubes (due to tubal adhesions, fimbrial phimosis, and/or infections, etc.) were excluded.

HMs were not removed and the clinical diagnosis was based on visual examination only. They were measured using a sterile ruler during surgery and stratified into three size categories of $\leq 1,1-2$, or $>2 \mathrm{~cm}$. Patient age, menopausal status, and HM number, size, and location were recorded.

Data analysis was performed using SPSS for Windows, ver. 17.0 (SPSS Inc., Chicago, IL, USA) and presented as mean (range) \pm standard deviation or as numbers of cases and percentages, where applicable. Chi-square test was used to compare categorical variables. A $p$-value $<0.05$ was considered significant.
All patients who participated in this study were counseled appropriately, and written informed consent was obtained. This study was approved by the Selcuklu Medical Faculty Ethics Committee of Selçuk University. All procedures performed in the study were in accordance with the ethical standards of the institutional and/or national research committee and with the 1964 Helsinki declaration and its later amendments or comparable ethical standards.

\section{RESULTS}

A total of 1,361 patients were included in this study, of which 1,066 (78.3\%) were premenopausal and 295 (21.7\%) postmenopausal. The mean age was $39.3 \pm 14.7$ years (range, $18-80$ years). The overall prevalence of $\mathrm{HM}$ was $17.2 \%(\mathrm{n}=235)$, and that in the premenopausal and postmenopausal women were $18.9 \%$ and $11.5 \%$, respectively. The prevalence of HM among premenopausal women was significantly higher than that in postmenopausal women ( $p=0.003)$.

HMs were observed on the left fallopian tube in 146 of 235 (10.7\%) cases, on the right fallopian tube in 123 (9\%), and on both tubes in 34 (2.4\%) cases. Left-sided lesions were significantly more frequent than right-sided lesions $(\mathrm{p}<0.001)$. More than one HM was found on one side in 19 (1.4\%) cases. Approximately $96 \%$ of the HMs were $\leq 1 \mathrm{~cm}$ in diameter and only in three $(0.2 \%)$ cases, they exceeded $2 \mathrm{~cm}$. Patient characteristics, HM prevalence, and surgical procedures are summarized in Table 1-2.

\section{DISCUSSION}

PTCs have been reported in all age groups from premenarche to menopause. ${ }^{6} \mathrm{HMs}$, which are usually $<2 \mathrm{~cm}$ in diameter, are classified as PTCs if pedunculated, and located near the fimbria of the fallopian tube. ${ }^{6}$ In our study of 1,361 patients, $96.1 \%$ of the HMs were $<1 \mathrm{~cm}$ in diameter, as reported by Kiseli et al., and only $0.2 \% \mathrm{HM}$ exceeded $2 \mathrm{~cm}$ in diameter. ${ }^{6}$ The overall prevalence of $\mathrm{HM}$ in our population, aged 18 to 80 years, was $17.2 \%$. The prevalence of HM in premenopausal 
(18.9\%) women was significantly higher than that in postmenopausal (11.5\%) women, suggesting that hormonal factors may predispose to HM development. Additionally, Muolokwu et al. found that the incidence of PTCs (including paraovarian cysts, hydrosalpinx, and HM) in a pediatric and adolescent population aged 1-19 years presenting with adnexal masses was $7.3 \%$, which is lower than that observed in our study cohort. ${ }^{5}$ Muolokwu et al. hypothesized that these remnants of the paramesonephric or mesonephric ducts increase in size under hormonal stimulation. ${ }^{7}$

Although most HMs are asymptomatic and found incidentally during operative procedures for other indications and thus thought to have no clinical significance, they can lead to clinically significant situations like adnexal torsion, malignancy, and infertility. ${ }^{2-4,8}$ To eliminate the risk of infertility and/or adnexal torsion, some gynecologists have recommended removing HMs that are found incidentally. ${ }^{5}$ The prevalence of HM is mostly unknown, and there is no evidence-based consensus among gynecologists concerning the management of these cysts. Providing medical evidence will add to the available information and demonstrate the utility of evidence-based medical data in all parts of clinical practice, including what some consider unimportant.

Rasheed and Abdelmonem found that $>50 \%$ of patients with unexplained infertility had HM, and also reported a 35\% (401 of 1,141) incidence rate of $\mathrm{HM}$ in women undergoing laparoscopy as part of an infertility investigation. ${ }^{2}$ Since a close fimbrio-ovarian relationship is a crucial factor for egg collection and conception, the displacement of the fimbriae from the ovulatory side due to its weight or disruption of tubal motility with respect to the pick-up and transport of the ovum may be the underlying mechanisms. ${ }^{2.49}$ Additionally, compression of the already narrow tubal lumen along with a lack of coordinated muscular contractions or ciliary activity of the fallopian tubes may contribute to this clinical scenario. ${ }^{10}$ Patients with unexplained infertility often have a high rate of spontaneous pregnancy after removal of the HM. ${ }^{2,4}$

Pansky et al. reported that HMs are involved in $26 \%$ of all adolescent cases of adnexal torsion. ${ }^{3}$ The torsion of an HM involving the ipsilateral fallopian tube has been implicated as a cause of acute abdominal pain in adolescents. ${ }^{11}$ It is not clear how HM contributes to the risk of adnexal torsion, although Cimador et al. and Seshadri et al. reasoned that HM may result in the free end of the tube becoming heavier, excessively mobile, and more susceptible to rotation. ${ }^{12,13}$

The strengths of the present study are its prospective nature, relatively large sample size, and novelty in terms of investigating the prevalence of HM over a broad age range. The main limitations of the study are the absence of pediatric and adolescent data, and the recruitment of all patients from only a single institution; thus, our results cannot be extrapolated reliably to other demographic groups or geographic locations. Although typical HMs are not difficult to diagnose on gross inspection, we did

\begin{tabular}{|c|c|c|c|c|}
\hline & Premenopausal & Postmenopausal & All & Distribution in patients with $\mathrm{HM}$ \\
\hline Patients & $1,066(78.3 \%)$ & $295(21.7 \%)$ & 1.361 & \\
\hline HM prevalences & 201 (18.9\%) & 34 (11.5\%) & $235(17.2 \%)$ & \\
\hline Left-sided HM & 125 & 21 & $146(10.7 \%)$ & $62 \%$ \\
\hline Right-sided HM & 106 & 17 & $123(9 \%)$ & $52 \%$ \\
\hline Both-sided HM & 30 & 4 & $34(2.4 \%)$ & $14 \%$ \\
\hline$\leq 1 \mathrm{~cm}$ & 193 & 33 & 226 & $96.1 \%$ \\
\hline $1-2 \mathrm{~cm}$ & 5 & 1 & 6 & $2.6 \%$ \\
\hline$>2 \mathrm{~cm}$ & 3 & - & 3 & $1.3 \%$ \\
\hline
\end{tabular}




\begin{tabular}{|ll|}
\hline & TABLE 2: Surgical procedures. \\
\hline Laparotomy & 1197 \\
Laparoscopy & 164 \\
\hline Benign & 1162 \\
Malignant & 199 \\
Gynecological & 414 \\
Obstetrical & 947 \\
\hline
\end{tabular}

not confirm our visual examination by histopathology. Additionally, we did not categorize the patients as fertile or infertile.

HM may be visualized by sonography if the cyst enlarges, undergoes torsion, hemorrhages, or becomes malignant. Since the specific diagnosis of these structures is usually not possible preoperatively $^{6}$, they may go unnoticed, particularly when they are asymptomatic and/or small. Therefore, many HM cases are confirmed only after laparotomy. ${ }^{14}$ A systematic examination and appraisal of the adnexa during pelvic surgery may help to accurately identify such common cysts. Instead of imaging methods, direct evaluation of the fallopian tubes seems to be a useful method to determine the prevalence of HM since most cysts are $<1 \mathrm{~cm}$ in diameter. The lower prevalence of $\mathrm{HM}$ after menopause indicates a hormonal role in stimulating HM development. Further multicenter prospective trials are needed to verify these findings in a larger population comprising of all age groups.

\section{Compliance with Ethical Requirements}

All procedures followed were in accordance with the ethical standards of the responsible committee on human experimentation (institutional and national) and with the Helsinki Declaration of 1975, as revised in 2008. The informed consent was obtained from all patients for being included in the study.

\section{Source of Finance}

During this study, no financial or spiritual support was received neither from any pharmaceutical company that has a direct connection with the research subject, nor from a company that provides or produces medical instruments and materials which may negatively affect the evaluation process of this study.

\section{Conflict of Interest}

No conflicts of interest between the authors and / or family members of the scientific and medical committee members or members of the potential conflicts of interest, counseling, expertise, working conditions, share holding and similar situations in any firm.

\section{Authorship Contributions}

Idea/Concept: Mustafa Gazi Uçar, Design: Mustafa Gazi Uçar; Control/Supervision: Çetin Çelik; Data Collection and/or Processing: Mustafa Gazi Uçar, Tolgay Tuyan İlhan, Ayhan Gül, Tansel Çakır, Gülşah Alkan Demir; Analysis and/or Interpretation: Tolgay Tuyan İlhan, Çetin Çelik; Literature Review: Mustafa Gazi Uçar; Writing the Article: Mustafa Gazi Uçar; Critical Review: Tolgay Tuyan İlhan, Ayhan Gül, Tansel Çakır, Çetin Çelik; References and Fundings: Mustafa Gazi Uçar, Ayhan Gül, Gülşah Alkan Demir; Materials: Tolgay Tuyan İlhan, Ayhan Gül, Tansel Çakır, Gülşah Alkan Demir.

\section{REFERENCES}

1. Nargund A, Majumdar S. Hydatid of Morgagni: sonographic resemblance with ectopic pregnancy. J Obstet Gynaecol 2014;34(5):4478.

2. Rasheed SM, Abdelmonem AM. Hydatid of Morgagni: a possible underestimated cause of unexplained infertility. Eur $\mathrm{J}$ Obstet Gynecol Reprod Biol 2011;158(1):626.

3. Muthucumaru M, Yahya Z, Ferguson P, Cheng $W$. Torsion of hydatids of Morgagni in premenarchal adolescent girls--a case report and re- view of literature. J Pediatr Surg 2011;46(9): e13-5.

4. Cebesoy FB, Kutlar I, Dikensoy E, Yazicioglu C, Kalayci H. Morgagni hydatids: a new factor in infertility? Arch Gynecol Obstet 2010;281(6): 1015-7.

5. Muolokwu E, Sanchez J, Bercaw JL, SangiHaghpeykar H, Banszek T, Brandt ML, et al. The incidence and surgical management of paratubal cysts in a pediatric and adolescent population. J Pediatr Surg 2011;46(11):21613.
6. Kiseli M, Caglar GS, Cengiz SD, Karadag D, YImaz MB. Clinical diagnosis and complications of paratubal cysts: review of the literature and report of uncommon presentations. Arch Gynecol Obstet 2012;285(6):1563-9.

7. Muolokwu E, Sanchez J, Bercaw JL, SangiHaghpeykar H, Banszek T, Brandt ML, et al. Paratubal cysts, obesity, and hyperandrogenism. J Pediatr Surg 2011;46(11):2164-7.

8. Song MJ, Lee CW, Park EK, Lee AW, Park JS, Hur SY. Parovarian tumors of borderline malignancy. Eur J Gynaecol Oncol 2011;32 (4):445-7. 
9. Hu C, Chen Z, Hou H, Xiao C, Kong X, Chen Y. Infertility evaluation via laparoscopy and hysteroscopy after conservative treatment for tubal pregnancy. Int J Clin Exp Med 2014;7(10):3556-61.

10. Yetkin Yıldııım G, Orta Korkut A, Köroğlu N, Susan Türkgeldi $L$. The relations between HSG proven tubal occlusion, stimulated intrauterine insemination and pregnancy rate. Balkan Med J 2017;34(1):60-3.
11. Origoni M, Cavoretto $\mathrm{P}$, Conti E, Ferrari $\mathrm{A}$. Isolated tubal torsion in pregnancy. Eur J Obstet Gynecol Reprod Biol 2009;146(2):11620.

12. Cimador M, Pensabene M, Siracusa F. Laparoscopic management of an isolated left fallopian tube torsion due to twisted Morgagni hydatid in a pre-menarcheal girl. Pediatr Med Chir 2014;36(2):90-2.
13. Seshadri S, Morris A, Uchil D, Joloaso A. Bilateral paratubal cysts with co-existent fallopian tube torsion in an adolescent. J Obstet Gynaecol 2009;29(6):564-5.

14. Kaido $Y$, Kikuchi A, Kanasugi T, Fukushima A, Sugiyama T. Acute abdomen due to ovarian congestion: a fallopian tube accompanied by a paratubal cyst, coiling tightly round the ovary. J Obstet Gynaecol Res 2013;39(1): 402-5. 